impression. The original fingermark was not damaged by this process.

These findings made sensational news. It was feared that astute money lenders would implant borrowers' thumbprints on fresh proforma and fill in larger amounts and/or higher rates of interest. When the case was referred to F. Brewester, the then Government Examiner of Questioned Documents, he submitted himself to a test prepared by Howrah Bar. The test consisted of 12 fingerprints - a random mix of genuine and transferred ones - on a single sheet of paper. He was asked to segregate them. In one attempt, Brewester identified the forged fingerprints. He noticed three differences: the transferred prints had diffuse lines while the originals had sharp patterns; the transferred prints were impregnated with gum; and the fibres on the part of the paper with transferred prints were disoriented.

Brewester therefore concluded that an observant fingerprint expert can easily differentiate an original mark from a transplanted one.

G. S. Sodhi* ${ }^{\star}$ Jasjeet Kaur $\dagger$

${ }^{*}$ S. G. T. B. Khalsa College, University of Delhi, Delhi-110007, India

$\dagger$ Rajguru College of Applied Sciences for Women, University of Delhi, Delhi-110095, India

\section{Science and government share anti-terrorist goals}

Sir-Your news article headlined "National academies slam Bush proposal for data security" (Nature 419, 769; 2002) mischaracterizes the debate here in Washington by its very title. It also leads readers to believe, erroneously, that I said that "without written guidelines, scientists can't accept [President Bush's science adviser, John] Marburger's assurances".

The statement "Science and Security in an Age of Terrorism", published on 18 October by the presidents of the National Academy of Sciences, the National Academy of Engineering and the Institute of Medicine, recognizes the need "to achieve an appropriate balance between scientific openness and restrictions on public information" when strategic secrets are at stake. But it also asks our government to maintain the current clear distinctions between classified and unclassified research, and recommends against poorly defined categories of "sensitive but unclassified" information that do not provide "precise guidance on what information should be restricted from public access".

The statement also asks the Bush administration to reaffirm a national security directive signed by President
Ronald Reagan in 1985 which held that "no restrictions may be placed upon the conduct or reporting of federally funded fundamental research that has not received national security classification".

In the wake of 11 September 2001, all of us in science and government have been forced to soberly reassess our roles concerning research touching on possible terrorist threats. No US scientist wants to publish research in a form that could be helpful to terrorists. Similarly, no US government official should want to hinder (or worse, stop) scientific research that might lead to effective tools against terrorism.

Scientists and government are listening to each others' legitimate concerns, and the government wants to enlist scientists in its anti-terrorism policies. In January, the National Academies plan to host a town meeting in which scientists, scientific publishers, national-security experts and government officials can talk face to face.

Marburger, director of the White House Office of Science and Technology Policy, is a key partner in these discussions. He informs us of the administration's concerns as well as communicating scientists' and scientific organizations' concerns to the White House. This is why I was disturbed at your implication that I said scientists couldn't rely on Marburger's assurances. That is simply wrong. The Bush administration has not yet even formulated its ultimate policy on this issue.

At the National Academies, we have never doubted Marburger's intentions or his goodwill. We share the same goal: to harness and focus the considerable energies of the science, engineering and health communities in the complex, rapidly changing challenge of counter-terrorism.

\section{E. William Colglazier}

National Academy of Sciences and National Research Council, 2101 Constitution Avenue Northwest, Washington DC 20418, USA

\section{Peer review to select academic job applicants}

Sir - Assessing the quality of candidates for academic positions has been the subject of controversy. Problems include nepotism and inbreeding, lack of impartiality among committee members - as M. Soler noted in Correspondence (Nature 411, 132; 2001) - and the increasing use of impact factors as indicators of research performance (see, as one of many examples, Nature 415, 726-729; 2002).

We suggest, as an alternative, that peer review could be a fairer method of research evaluation when scientists are being assessed for new jobs. To ensure the expertise and impartiality of peers, appointment committees should include internationally recognized scientists who are not affiliated with the institution where the position is offered.

Operational costs could be kept low by use of e-mail, the Internet, videoconferencing and so on. Such cost-effective implementation would be of particular benefit to academic institutions in developing countries, which could call on a broader choice of specialists to comprise virtual appointment committees.

Rigorous criteria, relevant to the position, could be laid down before the job is advertised. These criteria might include originality of ideas, diversity of approaches, appropriateness of methods, statistical design and analyses, and so on. Candidates could then be assessed on the kind of quantitative scale that many journals use.

To that end, a comprehensive account of the candidate's research contributions, together with relevant published papers, can be presented without the journals' or the candidate's identities being revealed, so research committees can focus on scientific quality irrespective of journals' impact factors and potential personal biases. Moreover, the identity of the committee should be made public, to safeguard the impartiality of the selection process and the confidence of candidates.

Peer review has undeniably contributed to the advancement of science by providing a reliable system of quality control validated by experts. Some of the criticisms of its use (such as plagiarism and competition) are unlikely to apply to the selection of new academic staff, as it is usually a candidate's past achievements rather than ideas, methods or data - that are under assessment.

No system is foolproof, and other criticisms of peer-review may apply to individual assessment — for example, sexism, opposing interests and lack of support for controversial ideas. However, these can be minimized by a policy of blind review, by having candidates specify potential conflicts of interest beforehand, and by including referees with different perspectives.

In summary, we believe that electronic information technologies can enhance the quality of recruitment systems in academic institutions by enabling the widespread use of peer review. This would be an improvement on current methods such as the impact factor, which is not a reliable measure of scientific excellence.

Esteban Fernández-Juricic, Wladimir J. Alonso, Cynthia Schuck-Paim

Department of Zoology, University of Oxford, Oxford OX1 3PS, UK 